\title{
Formação de Professores e Monitores de Alunos com Necessidades Educacionais Especiais
}

\author{
Formación de Profesores y Monitores de Alumnos con Necesidades \\ Educativas Especiales
}

Teacher Training and Student Monitors with Special Educational Needs

\author{
Claudete Botelho Ferreira ${ }^{1}$
}

\begin{abstract}
Resumo
O presente artigo intenciona apresentar uma abordagem sobre uma pesquisa-interventiva em seu processo de realização, uma vez que a pesquisa ainda está em andamento, não apresentando conclusões ou achados. Por se tratar de uma pesquisa realizada por uma mestranda profissional, o foco está relacionado à sua atuação numa escola municipal, dentro da área da educação especial, mais especificamente, na sua atribuição enquanto professora do atendimento educacional especializado. A escolha do tema está relacionada à formação de professores e monitores de educação especial por meio de grupo de estudos, tendo como referencial teórico os estudos de Vygotski sobre a defectologia A apresentação de aspectos legais sobre inclusão dá início ao relato, seguidos de um estudo sobre monitores escolares e a definição de atribuições destes sujeitos na escola, orientados pelos gestores da sala de aula, os professores e subsidiados pelos profissionais do atendimento educacional especializado, e em consonância com a proposta pedagógica da escola.
\end{abstract}

Palavras chave: atendimento educacional especializado; defectologia; formação; grupos de estudos.

\section{Resumen}

El presente artículo se propone presentar un enfoque sobre una investigación-intervencionista en su proceso de realización, una vez que la investigación todavía está en marcha, no presentando conclusiones o hallazgos. Por tratarse de una investigación realizada por una maestría profesional, el foco está relacionado a su actuación en una escuela municipal, dentro del área de la educación especial, más específicamente, en su atribución como profesora de la atención educativa especializada.La elección del tema está relacionada con la formación de profesores y monitores de educación especial por medio de un grupo de estudios, teniendo como referencial teórico los estudios de Vygotski sobre la defectologia. La presentación de aspectos legales sobre inclusión da inicio al relato, seguidos de un estudio sobre monitores escolares y la definición de atribuciones de estos sujetos en la escuelaorientados por los gestores del aula, los profesores y subsidiados por los profesionales de la atención educativa especializada,y en consonancia con la propuesta pedagógica de la escuela.

Palabras clave: atención educativa especializada; defectología; formación; grupos de estudios.

\begin{abstract}
The present article intends to present an approach on a research-interventional in its realization process, since the research is still ongoing, presenting no conclusions or findings. Because it is a research carried out by a professional master's degree, the focus is related to its performance in a municipal school, in special educationarea, more specifically, in its attribution as teacher of the specialized educational service. The themechoice is related to the training of teachers and monitors of special education through studiesgroup, having as theoretical reference the studies of Vygotski on defectology. The presentation of legal aspects on inclusion starts the story, followed by a study on school monitors and the definition of thesesubjectsattributionsin school,
\end{abstract}

\footnotetext{
${ }^{1}$ Pedagoga graduada pela Universidade Católica de Pelotas com especialização em Atendimento Educacional Especializado pela Universidade Federal do Ceará e mestranda do curso de Mestrado profissional da Universidade Federal do Pampa - campus Jaguarão.Resumo
} 
guided by the managers of the classroom, the teachers and subsidized by professionals of the specialized educational service, and in line with the pedagogical proposal of the school.

Keywords: specialized educational services; defectology; formation; study groups.

\section{Introdução}

A inclusão de crianças com necessidades educacionais especiais (NEE) na rede regular de ensino requer a elaboração de propostas escolares que vão além do espaço da sala de aula, carece de ações que instiguem todos os envolvidos no processo escolar inclusivo a refletir, planejar e (re)planejar ações pedagógicas inclusivas. Neste sentido, a ideia de realizar uma intervenção junto aos professores e monitores de alunos com necessidades educacionais especiais tornou-se necessária. A proposta objetiva estudar o potencial dos grupos de estudos, desenvolvidos na perspectiva do trabalho colaborativo, para a formação de professores e monitores de alunos com NEE.

Atuo no magistério há 27 anos na rede estadual de ensino do Rio Grande do Sul e há 22 anos na rede municipal de ensino do município de Arroio Grande, no extremo sul do estado acima citado. Sou pedagoga, graduada pela Universidade Católica de Pelotas e pósgraduada em Atendimento Educacional Especializado (AEE) pela Universidade Federal do Ceará. Atualmente, sou professora na rede estadual de uma turma de $5^{\circ}$ ano do ensino fundamental e desempenho minhas funções na rede municipal como professora do Atendimento Educacional Especializado (AEE) na Escola Municipal de Ensino Fundamental Presidente João Goulart.

No desempenho das minhas funções no AEE, o interesse em aprofundar os conhecimentos sobre educação inclusiva tornou-se imprescindível. A partir das constantes inquietações sobre as próprias práticas pedagógicas, o estudo e a análise de assuntos relacionados à educação especial, fizeram-se necessários.

Os grupos de estudos, na perspectiva do trabalho colaborativo, foram escolhidos como proposta de intervenção. A ideia surgiu como sugestão do grupo de pesquisa Educação Inclusiva e defectologia de Vigotsky, da Universidade Federal do Pampa - UNIPAMPA, campus Jaguarão, ao qual faço parte. A escola municipal de ensino fundamental Presidente João Goulart, que foi definida como espaço para realização da pesquisa interventiva, conta com a atuação de monitores escolares. Sendo assim, o trabalho de orientação destes sujeitos passa a ser de responsabilidade minha, enquanto professora de AEE, também.

Observando a atuação destes monitores, junto aos alunos com NEE na escola, percebi que se fazia necessária uma análise mais aprofundada de questões pertinentes às suas 
atuações. Para apropriação de dados que confirmassem tais constatações, foi realizada uma entrevista com os sujeitos envolvidos. No ano de 2017, foram realizadas entrevistas com os cinco monitores que atuaram naquele ano na escola. Em 2018, realizou-se um diagnóstico, através de questionamentos feitos aos colegas professores das salas regulares com relação às possíveis orientações dadas aos monitores com os quais têm contato em suas turmas. Os aspectos analisados nas entrevistas reafirmaram a necessidade de uma intervenção junto aos monitores, visto que ficou explícito os seus despreparos para o desempenho de suas funções junto aos alunos com NEE e, também, com os professores responsáveis por cada sala de aula, devido à dificuldade deles em identificar as atribuições dos monitores.

\section{Aspectos Legais da Educação Especial}

A Constituição Federal de 1988 define, no artigo 205, “a educação como um direito de todos, garantindo o pleno desenvolvimento da pessoa, o exercício da cidadania e a qualificação para o trabalho". No seu artigo 206, inciso I, estabelece a "igualdade de condições de acesso e permanência na escola" como um dos princípios para o ensino e garante como dever do Estado, a oferta do atendimento educacional especializado, preferencialmente na rede regular de ensino (art. 208). O caderno Orientações para Implementação da Política Nacional de Educação Especial na Perspectiva da Educação Inclusiva (BRASIL, 2015, p. 7), destaca que:

O Ministério da Educação - MEC, com base dos marcos legais políticos e pedagógicos da educação inclusiva, atua para assegurar o direito de todos à educação regular. Em 2008, estabelece a Política Nacional de Educação Especial na perspectiva da Educação Inclusiva, documento orientador para estados e municípios organizarem suas ações no sentido de transformarem seus sistemas educacionais em sistemas educacionais inclusivos. Além de decretos e resoluções, há um conjunto de documentos - notas técnicas e pareceres - que auxiliam na efetivação dos compromissos estabelecidos pela Convenção sobre os Direitos das Pessoas com deficiência. Estes documentos, oriundos de demandas dos sistemas de ensinos e sociedade em geral, estão disponíveis neste caderno, organizado para auxiliar e subsidiar as discussões, ações e o controle social das políticas públicas voltadas à inclusão escolar das pessoas com deficiência, transtornos globais do desenvolvimento, altas habilidades/superdotação.

Além da legislação citada, a Declaração de Jomtien (1990), em seu Artigo $1^{\text {o }}$, define que "cada pessoa - criança, jovem ou adulto - deve estar em condições de aproveitar as oportunidades educativas voltadas para satisfazer suas necessidades básicas de aprendizagem". Também, a partir da Declaração de Salamanca de 1994, a educação especial passou a ser estudada, analisada e entendida de forma mais ampla, considerando cada criança como única, com suas potencialidades a serem identificadas e valorizadas, bem como tratando suas limitações com possibilidades de superação. A declaração enfatiza que a educação deve 
considerar que "as crianças e jovens com necessidades educativas especiais devem ter acesso às escolas regulares, que a elas se devem adequar através duma pedagogia centrada na criança, capaz de ir ao encontro destas necessidades" (DECLARAÇÃO DE SALAMANCA, 1994, p. 1-2).

A Política Nacional de Educação Especial na Perspectiva Inclusiva (BRASIL. 2013, p.135) estabelece que o poder público, por meio das instituições de ensino, deve proporcionar todas as condições necessárias à aprendizagem dos alunos com necessidades educacionais especiais (NEE), perpassando por acessibilidade estrutural dos espaços físicos, profissionais habilitados e propostas pedagógicas condizentes. A Convenção sobre o Direito das Pessoas com Deficiência (ONU 2006), ratificada no Brasil pelo Decreto 6949/2009, (BRASIL, 2009), em seu artigo $9^{\circ}$, afirma que:

A fim de possibilitar às pessoas com deficiência viver com autonomia e participar plenamente de todos os aspectos da vida, os Estados Partes deverão tomar as medidas apropriadas para assegurar-lhes o acesso, em igualdade de oportunidades com as demais pessoas, ao meio físico, ao transporte, à informação e comunicação, [...] (BRASIL, 2009).

A inclusão dos educandos com NEE no ensino regular requer a elaboração de propostas escolares que contemplem as particularidades inerentes às pessoas visando a superar as barreiras existentes no contexto escolar para que estes alunos aprendam os conteúdos da escolarização. Para Sartoretto (2013, p. 77-8) "qualquer procedimento, pedagógico ou legal, que não tenha como pressuposto o respeito à diferença e a valorização de todas as possibilidades da pessoa deficiente não é inclusão". A questão norteadora do processo educacional, numa perspectiva inclusiva, deve legitimar as diferenças, com práticas pedagógicas diferenciadas (quando necessário), em uma mesma sala de aula, para que os alunos com NEE se apropriem de conceitos. Para que essa apropriação se efetive deve-se considerar que os conteúdos escolares, "mais do que a soma de certas conexões associativas formadas pela memória [...] mais do que um simples hábito mental; é um ato real e complexo de pensamento que não pode ser ensinado por meio de treinamento" (Vygotsky 2007, p. 104), e exige muito mais que apenas transmissão de teorias do professor para o aluno, carecendo considerar informações externas e a capacidade intelectual própria da criança.

A escola, em todos os seus seguimentos, deve planejar e executar ações que busquem efetivar a aprendizagem de todos os alunos. A Lei de Diretrizes e Bases da Educação Nacional (BRASIL, 1996), em seu artigo 12, inciso I, define que "os estabelecimentos de ensino, respeitadas as normas comuns e as do seu sistema de ensino, terão a incumbência de elaborar e executar sua proposta pedagógica”. 
Para os alunos com NEE, pode ser fundamental a participação do profissional de AEE. A Resolução n. 4, de 2009 (BRASIL, 2009) estabelece como atribuição do AEE identificar, elaborar e organizar recursos pedagógicos e de acessibilidade que eliminem barreiras para a plena participação dos alunos, considerando suas necessidades específicas. Ele deve ser articulado com a proposta da escola regular, embora suas atividades se diferenciem das realizadas em salas de aula de ensino comum. As Diretrizes Operacionais para o Atendimento da Educação Básica, na modalidade Educação Especial, em seu Art.2º estabelece:

O AEE tem como função complementar ou suplementar a formação do aluno por meio da disponibilização de serviços, recursos de acessibilidade ou estratégias que eliminem barreiras para sua plena participação na sociedade e desenvolvimento de sua aprendizagem (BRASIL, 2009, p.17)

A Nota Técnica No 123/2013/MEC/SECADI/DPEE (BRASIL, 2013, p. 69-70) define que o profissional de AEE deve ter formação inicial que o habilite para o exercício da docência e formação específica na educação especial, inicial ou continuada. Uma de suas atribuições é "estabelecer a articulação com os professores da sala de aula comum e com demais profissionais da escola" (NOTA TÉCNICA No 11 / 2010 / MEC / SEESP / GAB, p. 195), visando à participação dos alunos em todas as atividades escolares.

A Lei 13.146/2015 (Lei Brasileira de Inclusão da Pessoa com Deficiência) em seu Capítulo IV, Art. 28, Inciso XVIII prevê "a oferta de profissionais de apoio escolar" aos alunos com NEE (BRASIL, 2015, p. 8). De acordo com a Nota Técnica $\mathrm{n}^{\circ}$ 19/2010/MEC/SEESP/GAB, “o profissional de apoio deve atuar de forma articulada com os professores do aluno público alvo da educação especial, da sala de aula comum, da sala de recursos multifuncionais, entre outros profissionais no contexto da escola" (BRASIL, 2015, p. 145). Neste sentido, há a necessidade desses profissionais na escola, que neste texto são identificados como monitores, para criarem, juntos, estratégias que visem a atender as necessidades dos alunos.

Reafirmando esse direito, a lei $\mathrm{n}^{\circ}$ 12.764/12, Estatuto da Pessoa com Transtorno Global, nos termos do art. $3^{\circ}$, Parágrafo único, estabelece que: "Em casos de comprovada necessidade, a pessoa com transtorno do espectro autista incluída nas classes comuns de ensino regular terá direito a acompanhante especializado” (BRASIL, 2016c, p. 02).

A necessidade de uma pesquisa interventiva, após a análise situacional da escola, bem como de todos os aspectos legais aqui abordados reforçam a ideia da necessidade de formação de grupo de estudos numa perspectiva colaborativa. 


\section{Metodologia}

Uma proposta interventiva faz-se necessária quando, após diagnosticado um problema ou uma situação deficitária, carece de análise, estudo, ações e avaliações. O professor é, ou deveria ser, um eterno pesquisador de suas próprias práticas pedagógicas, visando a superar os desafios do cotidiano escolar.

No caso da pesquisa realizada por professores em atuação e sobre a sua própria prática pedagógica, Lüdke, da Cruz e Boing (2009) afirmam que a "possibilidade de um professor da educação básica realizar pesquisa é algo que vem suscitando significativo debate no meio universitário". Embora vários autores considerem-na importante, não a assumem como algo imprescindível.

Já Zeichner e Nofke (2001) evidenciam como aspecto positivo desse tipo de pesquisa a elaboração de conceitos reflexivos por parte do professor. Com relação aos aspectos negativos salientam:

a falta de preparação adequada dos professores para o bom desempenho em pesquisa, o que ocorre para que seus trabalhos sejam considerados menos rigorosos do que os obtidos pela pesquisa acadêmica; o valor questionável desse tipo de pesquisa, feita pelo professor, pela dificuldade de generalização a partir da análise de situações restritas; e a falta de tempo disponível para que o professor se dedique a essa prática (ZEICHNER e NOFKE. 2001).

De qualquer forma é inegável a importância da pesquisa por parte dos professores atuantes sobre seu próprio trabalho para a produção de conhecimentos e apropriação de teorias que embasem suas práticas pedagógicas. Como afirma André (2006):

[...] o professor deixa de ser um mero transmissor de saberes para atuar como um profissional prático reflexivo, capaz de analisar situações-problema e tomar decisões fundamentadas numa perspectiva teoria-crítica, e em pesquisas que tomam seu campo profissional como objeto de estudo (ANDRÉ. 2006).

Como referem Lüdke e André (1986) e Santos (1999, 2002), investigar é um esforço de elaborar conhecimento sobre aspectos da realidade, na busca de soluções para os problemas expostos. Para que a investigação se torne eficaz a utilização de procedimentos metodológicos faz-se necessária.

O plano de ação escolhido para a formação foi a realização de grupos de estudos, na perspectiva do trabalho colaborativo, entre professores e monitores.

Segundo Bonnefond, Bonnemain, Fontes e Clot (2016, p. 44) o estudo, a análise e a tomada de decisão surge a partir de uma necessidade, de uma demanda. Afirmam também que "dialogue becomes the preferred tool of practical performance". Faz-se necessário, então, o conhecimento da realidade do ambiente escolar da intervenção, bem como as concepções dos 
profissionais envolvidos para, só assim, traçar metas e procedimentos de ação, pois, como afirmam os já citados autores:

[...] it is understood that the problems had no reason to remain untouched. They can be discussed and solutions can be found: dialogue is a means of enriching the organization of work and bringing untreated problems to light. Also, if dialogue is an instrument, it is also a result because it helps you develop a shared experience where you can talk about work problems without escaping from them, as difficult to solve as the problems can be. It is necessary to emphasize that these benefits are not possible if the dialogue is not followed by concrete actions (BONNEFOND, BONNEMAIN, FONTES e CLOT 2016, p. 51).

A necessidade da intervenção se fortalece, então, pois não basta diagnosticar situações insatisfatórias dentro do ambiente escolar, sem sequer apontar alternativas de melhoria ou, melhor ainda, construir junto com o grupo, propostas que visem a superar as dificuldades mencionadas pelo próprio grupo e assumidas para si a responsabilidade de saná-las.

A ideia de grupos de estudos, na perspectiva do trabalho colaborativo, nesse sentido, fortalece a intenção de buscar, junto com os envolvidos com os alunos com NEE, conhecimento, possibilidades de crescimento e, principalmente, a realização de um trabalho em conjunto.

\subsection{A organização dos encontros}

Foram realizados 06 encontros, no horário das $11 \mathrm{~h}$ às $12 \mathrm{~h}$. Caso percebe-se a necessidade, outros encontros poderiam ocorrer. A proposta de trabalho escolhida foi a realização de grupo de estudos de situações cotidianas da educação inclusiva, estudo de casos. No primeiro encontro, o caso apresentado foi elaborado pela pesquisadora, baseado nas suas práticas pedagógicas enquanto professora de AEE. Posteriormente, os participantes foram instigados a relatar casos de suas vivências, que serviram de subsídios para os demais encontros. O professor Sérgio de Freitas Oliveira, na apresentação da primeira edição da Revista Eletrônica Coordenação Pedagógica: Coletânea de Estudos de Casos, refere-se aos estudos de caso da seguinte forma:

Se existe problema, existe a necessidade de conhecê-lo e compreendê-lo para que possamos promover alguma forma de intervenção. Afinal, superar as situações que comprometem o desenvolvimento dos nossos alunos deve ser sempre o objetivo do educador, o compromisso do professor e do pedagogo. Para isso, nós, pedagogos, recorremos ao estudo de caso, para fazermos um diagnóstico do problema, conhecermos seu alcance e suas implicações e sugerirmos intervenções - de curto, médio e longo prazo - que possam resultar em benefício para os nossos alunos (OLIVEIRA, 2008, p. 15).

Com o intuito elucidar situações que careçam intervenção e proporcionar o confrontamento entre teoria e prática, os estudos de caso fizeram parte do grupo de estudos, 
mediados pela pesquisadora. Foram definidos como teoria, excertos da defectologia de Vygotski.

O estudo da defectologia baseado em Vygotski, referentes ao Tomo V - Obras Escogidas - Fundamentos de defectología (1997), tem como primeiro aspecto significativo o termo defectologia, que, num primeiro momento pode causar estranheza, pois está relacionado à palavra defeito. Defeito, então, refere-se às deficiências, sejam elas físicas ou intelectuais. Essa percepção merece destaque pelo fato de que é papel da escola não se deter ao defeito, não se adaptar a ele, muito pelo contrário, lutar para superar as insuficiências das crianças. Vygotski deixa muito clara a importância do estímulo à superação das limitações da criança:

[...] a dinâmica do desenvolvimento da criança com uma insuficiência, partindo da posição fundamental de que o defeito implica uma dupla influência no desenvolvimento da criança. De um lado, é uma insuficiência e age diretamente como tal, criando danos, obstáculos, dificuldades na adaptação da criança. Por outro lado, precisamente porque o defeito cria obstáculos e dificuldades no desenvolvimento e altera o equilíbrio normal, serve como estímulo para o desenvolvimento de caminhos indiretos de adaptação, para o desenvolvimento de funções de rodeios, substitutas ou superestruturadas, que tendem a compensar a insuficiência e para produzir uma nova ordem em torno do sistema de equilíbrio alterado (VYGOTSKI, 1997, p. 187).

Para o pedagogo deve ficar claro que a sua intervenção, junto aos alunos com NEE, no sentido de possibilitar condições para o desenvolvimento de suas potencialidades e habilidades é de fundamental importância. A escola precisa ser mais significativa para o deficiente intelectual do que para uma criança normal, pois ele depende da escola para desenvolver seu pensamento, caso fique abandonado a própria sorte, não se apropriará dele. Para P. P. Blonski:

[...] um idiota, privado de educação, conhece suas possibilidades e, portanto, não sofre menos, mas mais do que uma criança normal. Se tentarmos expressar de forma positiva o que é dito aqui de maneira negativa, podemos levar um idiota a uma educação adequada, especialmente organizada e racional, na medida em que suas possibilidades não ganhem menos do que uma criança normal. A educação é mais necessária para a criança retardada do que para a normal - esta é a ideia fundamental de toda a pedagogia contemporânea (VYGOTSKI, 1997, p. 242).

Esta fala clarifica e evidencia o papel fundamental que a escola pode exercer na vida de uma criança deficiente. Com a ajuda da educação, a criança tem a possibilidade de cumprir as exigências de sua formação enquanto pessoa. Cabe salientar aqui, que os professores têm que se empenhar para oferecer aos alunos com NEE, não apenas conhecimentos reduzidos, mínimos, mas estimulá-los a pensar, a querer ir sempre além. A criança precisa sentir necessidade de pensar, se as dificuldades organizadas pelos professores obrigarem os alunos a 
pensar antes de atuar, a tomar consciência, como disse Claparède, ele avança, ele supera seus limites.

A superação destes limites está muito relacionada com a coletividade. Krasusski afirma que as crianças têm tendência a formar coletividades quando encontram indivíduos com diferentes níveis intelectuais. Neste sentido o trabalho colaborativo é riquíssimo para o estímulo e o desenvolvimento das potencialidades das crianças. De acordo com o autor:

O mais intelectualmente dotado adquire a possibilidade de manifestar uma atividade social maior, proporcional aos menos dotados e menos ativos. Por outro lado, esta última, por sua vez, extrai das relações sociais com os mais dotados e ativos, aquilo que para ele se torna inacessível, o que geralmente é um ideal inconsciente para o qual tende a ser na criança intelectualmente insuficiente (VYGOTSKI, 1997, p. 245).

Portanto, o único caminho, cientificamente válido para o aluno deficiente, é a educação social. O curso do desenvolvimento da criança com deficiência passa pela comunicação e a colaboração, pela interação, pelo estabelecimento das relações com as outras pessoas.

Sendo a escola um espaço de manifestações culturais, de diversidade, de troca, de apropriação do conhecimento, o desenvolvimento e a formação da criança revela-se como um processo orientado, chamado educação (grifo da autora).

Cada etapa dos encontros foi observada pela pesquisadora, tendo sido escolhida a metodologia da observação participante, que na ótica de Martins:

Trata-se de estabelecer uma adequada participação dos pesquisadores dentro dos grupos observados de modo a reduzir a estranheza recíproca. Os pesquisadores são levados a compartilhar os papéis e os hábitos dos grupos observados para estarem em condição de observar fatos, situações e comportamentos que não ocorreriam ou que seriam alterados na presença de estranhos (MARTINS, 1996, p. 268).

O fato de eu ser professora da escola, no qual o grupo de estudos aconteceu, a partilha de dados observados foi possível e enriqueceu o trabalho. Nesse caso, segundo Lüdke e André:

O "observador como participante" é um papel em que a identidade do pesquisador e os objetivos do estudo são revelados ao grupo pesquisado desde o início. Nessa posição, o pesquisador pode ter acesso a uma gama variada de informações, até mesmo confidenciais, pedindo cooperação ao grupo. Contudo, terá em geral que aceitar o controle do grupo sobre o que será ou não tornado público pela pesquisa (LÜDKE e ANDRÈ, 1996, p. 29, grifo das autoras).

Considero-me aqui um "observador participante", que, ao mesmo tempo, que ouvia os monitores e professores, intervinha e instigava-os à participação, fazendo observações e falas para que o grupo mantivesse o foco nas atividades propostas. 
Os registros das observações foram feitos em cadernos - diários. Para Zabalza (1994, p. 95) "a linguagem escrita representa um novo e poderoso instrumento de pensamento". Os escritos, por parte dos participantes do grupo de estudo, tanto no momento dos encontros, como em outros momentos, possibilitaram a reflexão e o registro de suas percepções, constatações, indagações, enfim, tudo que foi considerado pertinente e que pudesse contribuir para a proposta de trabalho, sendo eles significativos ou não para a pesquisa. Esses relatos serão analisados posteriormente. Pelo fato de os registros serem feitos por mim, remeto-me às constatações pessoais, ou seja, particular, própria da visão de quem observa.

Os diários como afirmam Porlán e Martin, podem ser entendidos, também, como "um guia de reflexão sobre a prática, favorecendo a tomada de consciência do professor sobre seu processo de evolução e sobre seus modelos de referência" (Porlán e Martín, 1997, p.19 - 20). Os diários foram entregues à pesquisadora para análise e registro, ao final do último encontro. Eu também fiz uso do diário.

\subsubsection{Estrutura dos encontros:}

Os encontros tiveram a seguinte estrutura:

$1^{\mathrm{o}}$ momento: Realização de dinâmicas relacionadas ao caso a ser abordado;

$2^{\circ}$ momento: Apresentação de situações (casos) cotidianas relacionadas à atuação dos professores e monitores na escola, junto aos alunos com NEE, para ser analisada;

$3^{\circ}$ momento: Explanação de situações vividas pelos participantes do grupo, a exemplo das situações citadas no momento anterior;

$4^{\circ}$ momento: Apresentação de excertos referentes à defectologia, baseado na teoria de Vygotski, confrontando teoria e prática;

$5^{\circ}$ momento: Confrontamento entre teoria e prática;

$6^{\circ}$ momento - Avaliação dos encontros: Registros das percepções e apontamento das contribuições da teoria para as práticas educativas.

\subsection{Avaliação dos encontros}

Os encontros serão avaliados a partir da análise dos dados coletos nas entrevistas, nas transcrições das gravações dos encontros, nos escritos feitos pelos participantes nos diários pela pesquisadora, além dos dados obtidos em conversa via recursos de mídia (WhatsApp). Considerando as mídias importantes no sentido de agregar diferentes elementos às relações atuais, estreitando possibilidades de comunicação e otimizando tempo, o uso de recursos 
midiáticos é impossível de ser negado na atual conjuntura social. As mídias constituem-se uma importante ferramenta. Santos e Santos afirmam que:

[...] podemos pensar as tecnologias digitais como condicionantes de novas formas de agir e pensar, condicionantes de novos processos culturais, no sentido de dar condições para outras aberturas comunicacionais e educacionais. A comunicação em rede, os softwares sociais e suas interfaces caracterizam os usos dos praticantes imersos no cotidiano, nas ruas, nas praças, na universidade, nas escolas, e definem uma nova lógica comunicacional (SANTOS e SANTOS, 2012, p. 180).

E não fora deste contexto está a escola, o que justifica e fortalece o uso das mídias nos espaços escolares.

A análise de todos os dados coletados ocorrerá com o apoio da disciplina de Análise Textual de Dados, que será ofertado pela Unipampa, no segundo semestre do ano letivo de 2019.

\section{A formação de professores e monitores}

Como já exposto anteriormente, a necessidade de formação inicial e habilitação adequada para atuar junto aos alunos com NEE está previsto na legislação brasileira vigente, bem como fica evidente na referida documentação que as atribuições e a forma de atuação do profissional de AEE são distintas, devendo ser consideradas como atividades complementares ou suplementares às atividades pedagógicas desenvolvidas em sala de aula, o que não significa que este profissional age sozinho, de forma isolada. Na realidade escolar hoje, na maioria dos casos, o professor de AEE tem formação inicial relacionada às licenciaturas e, como especialização, realiza um curso de 1 a 2 anos, com uma carga horária mínima de 360 horas, que pode incluir atividades à distância, o que, muitas vezes, é insuficiente para atuar na SRM. Rosseto critica a formação aligeirada desses profissionais e afirma que:

\footnotetext{
Por meio da educação especial, talvez seja possível buscar vias para superar o barateamento a que foi destinada a formação docente para o AEE. Algumas questões específicas da educação especial, como os conhecimentos que dizem respeito à área da surdez e à área visual, por exemplo, são indispensáveis ao professor. Mas há também conhecimentos necessários a todos os profissionais, como o estudo das bases teóricas que explicam o desenvolvimento humano e a pesquisa de referenciais que contemplam esse desenvolvimento na pessoa com deficiência (ROSSETO, 2015, p. $111-112$ ).
}

O conhecimento sobre a conjuntura educacional, o embasamento teórico para atuar junto aos alunos com NEE e a formação continuada são, ou deveriam ser, atribuições inerentes aos professores, tanto das salas de aula como de AEE. Rosseto, referindo-se a Vygotski (1983) reforça essa ideia da formação, explicitando que: 
Uma interpretação da ideia defendida pelo autor, que a relacione ao atual contexto da educação especial, nos permite compreender que, ao mesmo tempo em que não podemos reter os estudos da área num campo isolado como se fosse independente dos demais, eliminar os conhecimentos peculiares da educação especial também não é coerente. Para que o professor possa desenvolver uma ação pedagógica que contemple as necessidades dos alunos por meio da SRM é necessária uma formação que contemple a especificidade desse trabalho (ROSSETO, 2015, p. 11).

Enquanto pesquisadora e professora de AEE essa inquietação ficou mais evidente durante o curso de mestrado, e é o que justifica e norteia minha pesquisa.

\subsection{Os grupos de estudo na perspectiva do trabalho colaborativo}

No entendimento de que nas relações humanas, na troca de conhecimentos, vivências, experiências entre os pares um grupo se fortalece para atingir objetivos comuns, a ideia de realizar uma intervenção por meio de grupo de estudos, na perspectiva do trabalho colaborativo se fortalece. Freitas, embasando-se em Bakhtin e Vygotsky afirma que:

O outro é, portanto, imprescindível tanto para Bakhtin como para Vygotsky. Sem ele o homem não mergulha no mundo sígnico, não penetra na corrente e da linguagem, não se desenvolve, não realiza aprendizagens, não ascende às funções psíquicas superiores, não forma a sua consciência, enfim não se constitui como sujeito. $\mathrm{O}$ outro é peça importante e indispensável de todo o processo dialógico que permeia ambas as teorias (FREITAS, 1997, p. 320).

Pensar coletivamente requer uma disponibilidade entre os pares que não anule a individualidade, mas que propicie um crescimento das concepções e ideias e concepções particulares. Segundo Damiani (2008, p. 218) “o trabalho colaborativo entre professores apresenta potencial para enriquecer sua maneira de pensar, agir e resolver problemas, criando possibilidades de sucesso à difícil tarefa pedagógica".

Outro aspecto presente na atual conjuntura educacional é a necessidade de formação continuada, com o intuito de enfrentar os desafios diários da docência. Entender essa necessidade como parte importante de um processo coletivo é fundamental. Damiani, Porto e Schlemmer destacam que:

A cultura de colaboração se apresenta como um processo permanente, decorrente da compreensão da comunidade escolar sobre a complexidade da tarefa educativa e as consequentes necessidades de articulação dos educadores (professores e demais profissionais atuantes na escola), a fim de atender aos interesses coletivos e favorecer o crescimento profissional. Implica uma ação democrática e um trabalho colaborativo sem perder o foco na importância da liberdade de intervenção e do respeito à autonomia profissional de cada sujeito, autonomia que, assim como a identidade singular do docente, se constrói no respeito às diferenças, na diversidade das concepções teóricas e das práticas profissionais, condições para o desenvolvimento criativo - tanto individual quanto coletivo (DAMIANI, PORTO E SCHLEMMER, 2009, p. 165). 
Na perspectiva inclusiva, professores e monitores se vêm constantemente desafiados ao novo, ao desconhecido, uma vez que as necessidades dos alunos, bem como suas habilidades carecem de percepção, entendimento e, principalmente, conhecimento para elaborar estratégias pedagógicas condizentes para cada sujeito. Esse desafio, se enfrentado junto aos demais envolvidos no processo educativo escolar propiciará o crescimento de todos, não apenas dos alunos.

\section{Monitores escolares: quem são?}

Este item aborda aspectos legais e estruturais pertinentes à atuação dos monitores na escola, uma revisão teórica sobre o monitor e, também, o papel do professor na relação com os monitores.

\subsection{Os monitores em Arroio Grande}

No município de Arroio Grande não há documento que defina esse profissional. Os monitores escolares são alunos contratados em regime de estágio remunerado, como prestadores de serviços, para atuarem nas escolas de educação básica do município, junto aos alunos com NEE, através de um convênio firmado entre a prefeitura municipal de Arroio Grande e o Centro de Integração EmpresaEscola do RS (CIEE-RS), devidamente aprovados em um processo seletivo realizado pelo executivo municipal.

Conforme o edital da prefeitura, o processo seletivo destina-se à formação de cadastro de reserva de estágio remunerado em diversas áreas. Vale ressaltar que dentre as vagas do processo seletivo, acima citado, estão contempladas diversas áreas: educacionais, administrativas, técnicas, na área da saúde, dentre outras, sendo em nível médio ou superior. Sendo assim, é viável a contratação de profissionais que estejam cursando licenciatura.

O Contrato de prestação de serviços de n ${ }^{\circ} 62 / 2015$, em sua cláusula 03 estabelece que:

Cláusula 03 - O objetivo da contratação de serviço burocrático para manutenção e funcionalidade das atividades da Casa através de esquema de cooperação recíproca que dispõe a Lei 11.788/08 subsidiar estágios para os estudantes de ensino médio, médio técnico e superior, de interesse curricular, obrigatório ou não, entendido o estágio como uma estratégia de profissionalização que complementa o processo "Ensino Aprendizagem", conforme Projeto Básico em anexo ao processo de Dispensa 01/2015 (PREFEITURA MUNICIPAL DE ARROIO GRANDE, 2015, p. 1).

Para atender a demanda de profissionais de apoio nas mais diversas áreas da administração municipal, o executivo opta por contratar profissionais, em regime de estágio remunerado. Uma das áreas atendidas pelos estagiários é a educacional. Os monitores de alunos com NEE são contratados dessa forma que, após a realização do processo seletivo, os candidatos aprovados são selecionados pela secretaria de administração da prefeitura que, 
através do levantamento das necessidades realizado pela Secretaria Municipal de Educação (SME), designa os estagiários às escolas. Essas necessidades são encaminhadas pelas escolas à SME, no início de cada ano letivo, de acordo com a matrícula de alunos com NEE. Ao apresentarem-se na escola, os monitores são designados a atuar junto aos alunos com NEE. O critério de necessidade de apoio baseia-se no laudo médico, apresentado no ato da matrícula, ou ainda, parecer psicopedagógico.

Ao analisar os documentos de designação dos monitores, foi possível perceber que, em sua formação, eles apenas tinham concluído o ensino fundamental e estavam cursando o ensino médio. Os cursos em andamento, não tinham qualquer relação com a Pedagogia. Embora o processo seletivo, acima citado, apresente vagas para acadêmicos de pedagogia ou outras áreas afins com a educação, a escola Presidente João Goulart, nos anos de 2017 e 2018, só recebeu monitores cursando o ensino médio, sem qualquer embasamento teórico para atuar junto aso alunos com NEE.

\subsection{Uma revisão teórica sobre o monitor}

A educação inclusiva deve atender as especificidades de cada criança. Para que isso se efetive, todos os envolvidos no processo escolar devem atuar, de forma a construir e efetivar uma proposta pedagógica que contemple o sucesso de todos. A Declaração de Salamanca aponta que o "desafio para uma escola inclusiva é o de desenvolver uma pedagogia capaz de educar com sucesso todos os alunos, incluindo aqueles com deficiência e desvantagens severas" (SALAMANCA, 1994, p. 6). A necessidade de um profissional de apoio ao professor da sala regular, para atuar junto aos alunos com NEE é fundamental. Alei $\mathrm{n}^{\circ}$ 12.764/12, já citada na introdução determina tal necessidade.

Existem algumas nomenclaturas para definir esse profissional. Segundo o dicionário Aurélio, uma delas é "pessoa que orienta ou toma conta de um grupo de crianças ou de alunos." Outras nomenclaturas são utilizadas com o mesmo intuito como: tutor e cuidador escolar. Cordeiro (2018, p. 18) apud Botti e Rego (2008), descreve o monitor como um tutor:

O termo tutor vem do latim oris, um termo do direito romano, atribuído àquele que se encarregava de cuidar de um incapaz. Em português, a palavra já era usada no século XIII e tinha o significado de guarda, protetor, defensor, curador; significa também aquele que mantém outras pessoas sob sua vista, que olha, encara, examina, observa e considera é o que tem a função de amparar, proteger e defender, sendo o guardião, aquele que dirige e governa (BOTTI; REGO, 2008). 
Apresentam, também, a seguinte definição: “o tutor é considerado um guia, um facilitador que auxilia no processo de aprendizagem centrada no aluno" (BOTTI;REGO). Uma definição diferente aparece no texto de Santos, Pereira e de Farias, ao afirmarem que:

O Cuidador Escolar é o profissional que está inserido na interdisciplinaridade de diversas áreas do conhecimento, para inserir o educando com necessidades educativas especiais no contexto escolar, colaborando assim, com a perspectiva da educação inclusiva. Para que fique evidenciada a importância deste profissional, apresentado um caso concreto na área de educação especial (SANTOS, PEREIRA, DE FARIAS 2016, p. 04, grifos dos autores).

Vale ressaltar que nenhum documento refere-se a monitor com bidocente ou professor de turma, muito ao contrário, o que se percebe, claramente, em todos os documentos analisados é que se trata de um profissional que atua junto ao professor como apoiador, como auxiliar.

Como já foi dito antes, em virtude de o município de Arroio Grande não possuir a definição deste profissional em seu quadro de funcionários e, muito menos apresentar suas atribuições, neste estudo, entende-se monitor como um profissional especializado que acompanha os alunos com NEE, estando em consonância com o Estatuto da Pessoa com Transtorno Global.

O monitor tem contato direto com os alunos com NEE. Ele tem a responsabilidade de desenvolver atividades e orientá-lo em sala de aula, além de dar apoio nas atividades de higiene, alimentação, locomoção e entre outras que necessitem auxílio constante no dia a dia escolar (BRASIL, 2008). O monitor também é importante no que se refere à esfera emocional do aluno, por isso ele precisa transmitir confiança ao aluno e à família. Aranha (1994, p. 69 70) salienta que "é no cenário das relações sociais que se dá a apreensão do real, a construção do conhecimento, da sociedade e o desenvolvimento do homem".

O monitor acaba tendo uma relação muito próxima e estreita com o aluno com NEE e, por isso, passa a ser a principal referência dele na escola. Por considerar esse elo, esse vínculo fundamental para o desenvolvimento do aluno, é necessário que os monitores tenham consciência de seu papel no processo educativo dos alunos por eles acompanhados e que consigam realizar um trabalho em conjunto com o professor da sala de aula, o professor de AEE, bem como os demais profissionais da escola.

Cabe afirmar que a atuação deste profissional não substitui o professor titular da turma, muito pelo contrário, faz-se necessário que ambos atuem juntos e que o monitor tenha, no professor da sala de aula, sua primeira e principal referência, assim como o aluno com 
NEE. A necessidade de um planejamento em conjunto irá contribuir muito para o sucesso do aluno, mas a responsabilidade com o ensino é do professor.

\section{Considerações finais}

Destaco a relevância do tema em questão, visto que, a inclusão de alunos com NEE na rede regular de ensino é uma realidade nas escolas e, para atender de forma adequada e visando à aprendizagem dos alunos de forma igualitária, alguns mecanismos têm que serem adotados, um deles, sem dúvida nenhuma é a atuação dos monitores junto aos professores, sem negar que o gestor da sala de aula é o professor. Para atender essa demanda, outros aspectos estão sendo analisados e estudados, podendo citar aqui alguns deles como: a emergência dos monitores escolares e o papel do poder público; a responsabilidade política; a autonomia financeira das instituições de ensino; a gestão democrática, dentre outros.

Os dados obtidos na intervenção também estão em fase de análise, podendo adiantar que a necessidade de uma formação inicial e continuada aos professores e monitores de alunos com NEE é uma percepção fácil de ser identificada e unânime entre os participantes.

\section{Referências}

ANDRÉ, Marli. A Formação do Pesquisador da Prática Pedagógica. Revista Plurais. Salvador: v.1, n.1, p. 30-41, jan./abril. 2006.

ARANHA, M. S. F. A integração social do deficiente: analise conceitual e metodológica. Mesa redonda; a questão da integração do deficiente. XXIV Reunião Anual da Sociedade de Psicologia de Ribeirão Preto.SP,1994.

- Declaração de Salamanca. Linha de ação sobre necessidades educativas especiais. In: Conferência Mundial sobre Necessidades Educativas Especiais: Acesso e Qualidade. Brasília: Corde, 1994.

Lei $n^{\circ}$ 9.394, de 20 de dezembro de 1996 - Estabelece as Diretrizes e Bases da Educação Nacional, Brasília: 1996.

Política Nacional de Educação Especial na Perspectiva da Educação Inclusiva. Documento elaborado pelo Grupo de Trabalho nomeado pela Portaria $n^{\circ}$ 555/2007, prorrogada pela Portaria nº 948/2007. Brasília: 2008.

Decreto $n^{\circ}$ 6.949, de 25 de agosto de 2009. Promulga a Convenção Internacional sobre os Direitos das Pessoas com Deficiência e seu Protocolo Facultativo, assinados em Nova York, Brasília: 2009.

Resolução n. 04, de 02 de outubro de 2009. Institui as Diretrizes Operacionais para o Atendimento Educacional Especializado na Educação Básica - Modalidade Educação Especial. Ministério da Educação, Conselho Nacional de Educação. Brasília: 2009 a. 
Lei Federal $n^{\circ}$ 12.764, de 27 de dezembro de 2012. Institui a Política Nacional de Proteção dos Direitos da Pessoa com Transtorno do Espectro Autista; e altera o § 3o do art. 98 da Lei no 8.112, de 11 de dezembro de 1990. Diário Oficial [da] República Federativa do Brasil, Brasília, DF: 28 dez. 2012.

. Política Nacional de Educação Especial na Perspectiva da Educação Inclusiva. MEC/SECADI. Brasil, 2013.

Lei $n^{\circ} 13.146$, de 06 de julho de 2015. Institui a Lei Brasileira de Inclusão da Pessoa com Deficiência (Estatuto da Pessoa com Deficiência), Brasília: 2015.

.Orientações para implementação da política de educação especial na perspectiva da educação inclusiva. Brasília: 2015.

.Constituição da República Federativa do Brasil. Supremo Tribunal Federal, Atualizada até a EC n. 99/2017. Brasília, 2018. Disponível em www.stf.jus.br/arquivo/cms/legislacaoconstituicao/anexo/cf.pdf. Acesso em 23 dezembro 2018.

Declaração Mundial sobre educação para Todos: satisfação das necessidades básicas de aprendizagem. Jomtien, 1990. Disponível em unesco.org/images/0008/00862/086291 por.pdf. Acesso em: 30 abril. 2018.

BONNEFOND, J.Y; BONNEMAIN, A; FONTES, F. F; CLOT, Y. To institute conflictive cooperation on the quality of work. Educação Revista Quadrimestral. Porto Alegre: v. 39, n. esp. (supl.), s42-s53, dez. 2016. Disponível em http://dx.doi.org/10.15448/19812582.2016.s.24326. Acesso em: 09 maio. 2018.

BOTTI, S. H. de O. REGO, S. Preceptor, Supervisor, Tutor e Mentor: Quais são seus papéis? Revista Brasileira de Educação Médica, Rio de Janeiro: v.3, p. 363373, 2008.

Coletânea de Estudos de Casos: "O Caso é o Seguinte..." / Revista Eletrônica. Coordenação Pedagógica: / Pontifícia Universidade Católica de Minas Gerais - v. 1, n. 2 (ago./dez. 2008-). - MG/Belo Horizonte: ICH- PUC Minas, 2008. Disponível em portal.pucminas.br/graduacao/cursos/.../ARE_ARQ_REVIS_ELETR20081205200459.

Acesso em 22 dezembro 2018.

DAMIANI, M. F. Entendendo o trabalho colaborativo em educação e revelando seus benefícios. Educar, Curitiba, n. 31, p. 213-230, 2008. Editora UFPR.

DAMIANI, M. F; PORTO, T. M. E; SCHLEMMER, E.(Organizadoras)Trabalho colaborativo/cooperativo em educação: uma possibilidade para ensinar e aprender. São Leopoldo: Oikos; Brasília: Liber Livro, 2009.

DE FARIAS, A. L. P; DOS SANTOS, W; PEREIRA, L. G; A importância do cuidador escolar na educação de alunos com necessidades educativas especiais: da educação especial no modelo segregado a perspectiva da educação inclusiva. II CONGRESSO INTERNACIONAL DE EDUCAÇÃO INCLUSIVA. II JORNADA CHILENA DE EDUCAÇÃO INCLUSIVA. Campina Grande. Paraíba. 2016. Disponível em https://docplayer.com.br/53644054-A-importancia-do-cuidador-escolar-na-educacao. Acesso em novembro 2018. 
FREITAS, M. T. de A. Nos textos de Bakhtin e Vygotsky: um encontro possível. In: BRAIT, B. Bakhtin, dialogismo e construção de sentido. Campinas: Editora Unicamp,1997.

LÜDKE, Menga, Marli E.D.A. ANDRÉ. Pesquisa em educação: abordagens qualitativas São Paulo: $\quad$ EPU, $1986 . \quad$ Disponível https://edisciplinas.usp.br/mod/resource/view.php?id=2191564. Acesso em 16 dezembro. 2018.

MARTINS, J. B. Observação participante: uma abordagem metodológica para a psicologia escolar. Semina: Ci. Sociais/Humanas, Londrina, v. 17, n. 3, p. 266-273, set. 1996. Disponível em www.uel.br > Capa > v. 17, n. 3 (1996). Acesso em 20 dezembro 2018.

PORLÁN, Rafael \& MARTÍN, José. El diario del profesor. Sevilla: Díada Editora, 1997.

PREFEITURA MUNICIPAL DE ARROIO GRANDE. Secretaria Municipal de Administração. Edital Processo Seletivo. 2018.

ROSSETTO, E. Formação do professor do atendimento educacional especializado: a Educação Especial em questão. Revista Educação Especial | v. 28 | n. 51 | p. 103-116 | jan./abr. 2015 Santa Maria. Disponível em: http://www.ufsm.br/revistaeducacaoespecial. Acesso em 05 jan. 2019.

SANTOS R.S; SANTOS, E, O. Cibercultura: redes educativas e práticas cotidianas. Revista Eletrônica Pesquiseduca - p. 159-183, v.04, n. 07, jan.-jul.2012. Disponível em periodicos.unisantos.br > Capa > v. 4, n. 7 (2012). Acesso em 16 dezembro. 2018.

SARTORETTO, M. L. Inclusão: da concepção à ação. In: MANTOAN, M. T. E. (Org.). O desafio das diferenças nas escolas. Petrópolis: Vozes, 2013.

VYGOTSKI, L. S. Obras Escogidas V. Fundamentos da defectologia. In: La defectologia y la teoria del desarrollo y la educación del niño anormal. Madri Editorial Visor, 1997.

L. S. Obras Escogidas V. Fundamentos da defectologia. In: Tesis fundamentales del plan para el trabajo paidológico de investigación em el campo de la infância difícil. Madri Editorial Visor, 1997.

. L. S. Obras Escogidas V. Fundamentos da defectologia. Prólogo al libro de E. K. Grachova. Madri Editorial Visor, 1997.

A formação social da mente: o desenvolvimento dos processos psicológicos superiores. Organizadores Michael Cole et al. Tradução José Cipolla Neto, Luís Silveira Menna Barreto, Solange Castro Afeche. 7. ed. São Paulo: Martins Fontes, 2007.

ZABALZA, Miguel A. Diários de aula: contributo para o estudo dos dilemas práticos dos professores. Porto: Porto Editora, 1994. 